\title{
High Frequency of Microsatellite Instability in Intestinal-type Gastric Cancer in Korean Patients
}

\author{
Won Hyuk Choe, M.D., Sun-Young Lee, M.D., Jun Haeng Lee, M.D., \\ Sang Goon Shim, M.D., Young-Ho Kim, M.D., Poong-Lyul Rhee, M.D., \\ Jong Chul Rhee, M.D., Chang-Seok Ki, M.D. ${ }^{2}$, Jong-Won Kim M.D. ${ }^{2}$, \\ Sang Yong Song M.D. ${ }^{3}$ and Jae J. Kim M.D. \\ Departments of Internal Medicine, Laboratory Medicine ${ }^{2}$ and Pathology ${ }^{3}$, Samsung Medical Center, \\ Sungkyunkwan University School of Medicine, Seoul, Korea
}

\begin{abstract}
Background : Although there have been some reports on microsatellite alterations in gastric cancer, findings are inconsistent regarding the associations between histological classification and microsatellite instability (MSI). In the present study, we attempted to determine whether Lauren's histological subtypes are related with MSI status.

Methods : Paraffin-embedded tissue samples from 14 diffuse-type and 14 intestinal-type gastric adenocarcinomas were matched up according to patient gender and age. Mononucleotide markers (BAT25 and BAT26) and dinucleotide markers (D2S123, D5S346, and D17S250) were used for MSI analyses. Microsatellite genotypes were categorized in terms of high MSI incidence (MSI-H, $>30 \%$ positive marker) or low MSI incidence (MSI-L, $<30 \%$ positive marker). Losses of $h M L H 1$ and $h M S H 2$ protein expression were immunohistochemically studied.

Results : MSI-H was observed in 11 cases (78\%) of the 14 intestinal-type cases as compared to $3(21 \%)$ of the 14 diffuse-type cases $(p=0.007)$. In MSI-H tumors, 10 cases $(71 \%)$ showed losses of $h M L H 1$ protein expression, while 2 cases (14\%) in MSI-L tumors showed losses of $h M L H 1$ protein expression ( $p=0.006)$.

Conclusion : MSI-H tumors are more frequently found in intestinal-type gastric cancer, which suggests the possibility that there are different pathogenic pathways in gastric carcinogenesis according to histologic type.
\end{abstract}

Key Words : Gastric cancer, Histology, Microsatellite instability

\section{INTRODUCTION}

Gastric adenocarcinoma is one of the most frequently observed malignant tumors in the world, contributing significantly to cancer mortality, especially on the Asian continent ${ }^{1)}$. Recently, it became clear that gastric carcinogenesis is a multifactorial, multi-step process requiring sequential alterations in genes which codify for tumor suppressors, proto-oncogenes, gate-keeper genes, enzymes, growth factors, and membrane or nuclear receptors (the multi-hit hypothesis) ${ }^{2}$. Among these, mutation carriers of DNA mismatch repair genes exhibit a characteristic phenotype termed microsatellite instability (MSI), which is characterized by an accelerated accumulation of single nucleotide mutations and of alterations in the lengths of simple repetitive microsatellite sequences found throughout the genome $\mathrm{e}^{3-7)}$. In the past, MSI was considered to be restricted to the field of colorectal cancer ${ }^{3,4,8)}$. However, it has recently been reported that sporadic cancers, including gastric cancer, are also related with $\mathrm{MSI}^{5-8)}$. In Korea, several studies have suggested that susceptibility to gastric cancer is caused by mutations in one of the genes in the DNA mismatch repair system ${ }^{9-17)}$.

Gastric adenocarcinoma is classified as intestinal- or diffusetype according to histologic characteristics ${ }^{18}$. Intestinal-type adenocarcinomas are usually located in the distal stomach and

- Received : October 12, 2004

- Accepted : December 9, 2004

- Correspondence to : Jae J. Kim, M.D., Ph.D., Department of Internal Medicine, Samsung Medical Center, 50 Irwon-dong, Gangnam-gu, Seoul, 135-710, Korea Tel : 82-2-3410-3409, Fax : 82-2-3410-3849, E-mail : jjkim@smc.samsung.co.kr 
Table 1. Primer sequences of the microsatellite instability (MSI) markers

\begin{tabular}{|c|c|c|c|}
\hline Marker & Size (bp) & Dye & Primer Sequences \\
\hline BAT25 & 90 & Dye $A^{1}$ & $\begin{array}{l}\text { 5'-TCG CCT CCA AGA ATG TAA GT-3' } \\
\text { 5'-TCT GCA TTT TAA CTA TGG CTC-3' }\end{array}$ \\
\hline BAT26 & $80-100$ & Dye $B^{2}$ & $\begin{array}{l}\text { 5'-TGA CTA CTT TTG ACT TCA GCC-3, } \\
\text { 5'-AAC CAT TCA ACA TTT TTA ACC-3' }\end{array}$ \\
\hline D2S123 & $197-227$ & Dye $A^{1}$ & $\begin{array}{l}\text { 5'-AAA CAG GAT GCC TGC CTT TA-3' } \\
\text { 5'-GGA CTT TCC ACC TAT GGG AC-3' }\end{array}$ \\
\hline D5S346 & $96-122$ & Dye $C^{3}$ & $\begin{array}{l}\text { 5'-ACT CAC TCT AGT GAT AAA TCG GG-3' } \\
\text { 5'-AGC AGA TAA GAC AGT ATT ACT AGT T-3' }\end{array}$ \\
\hline D17S250 & $150-169$ & Dye $A^{1}$ & $\begin{array}{l}\text { 5'-GGA AGA ATC AAA TAG ACA AT-3' } \\
\text { 5'-GCT GGC CAT ATA TAT ATT TAA ACC-3' }\end{array}$ \\
\hline
\end{tabular}

${ }^{1}$ Dye A, 6-carboxyfluorescein; 'Dye B, 6-carboxy-4, 7, 2', 4', 5', 7'-hexachlorofluorescein; ${ }^{3}$ Dye C, 2, 7', 8'-benzo-5'-fluoro-2', 4, 7-trichloro-5-carboxyfluorescein

possess a characteristic glandular structure that is believed to arise from the intestinal metaplastic epithelium ${ }^{18)}$. In contrast, diffuse-type adenocarcinomas especially invade the cardia and have poor glandular formations that are believed to arise from gastric mucous cells ${ }^{18)}$. These two different types are considered to develop through different molecular pathways ${ }^{19,20)}$, raising the possibility that they may have different genetic background characteristics, such as MSI rates.

Although previous studies have reported variable MSI rates in the two major types of histological gastric cancer, findings have been inconsistent regarding the association of MSI with these two pathological features. Most reports have suggested that $\mathrm{MSI}$ is more frequently observed in the intestinal type $\mathrm{e}^{10,12 \text {, }}$ ${ }^{17,21-25)}$ but, some have also reported the opposite finding ${ }^{8,26,27)}$. These different results regarding $\mathrm{MSI}$ and intestinal/diffuse histotype may reflect ethnic, racial, or geographic differences, in addition to discrepancies due to different definitions of MSI cancer. Moreover, due to the lack of well-defined criteria for microsatellite analysis, different numbers or types of markers were used in each study. Recently, it has been reported that $\mathrm{MSI}$ was more frequently seen in gastric cancer from Korea ${ }^{16)}$. [MAR1]Therefore, we investigated MSI in gastric cancer in Korea according to Lauren's classification.

\section{MATERIALS AND METHODS}

\section{Patients}

A total of 28 gastric adenocarcinoma patients were retrieved among the gastric cancer patients who underwent gastrectomy in 1996 at Samsung Medical Center, Seoul, Korea. Fourteen cases of cardiac adenocarcinoma were selected first, and another 14 cases of antral adenocarcinoma were selected, matching for age and gender. None of the patients had any previous history of malignancy. The postoperative stages varied from stage IB to stage IV.

\section{DNA preparation}

Serial gastric sections from cancer tissue and adjacent noncancerous tissue were obtained at 5 um thickness and stained with hematoxylin and eosin. Only tissues containing more than $80 \%$ of cancer tissue were deemed acceptable for microsatellite analysis. Genomic DNA from tumors and from corresponding normal tissue were obtained from paraffin blocks by microdissection. Deparaffinization was done by xylene for 20 minutes and 40 minutes at room temperature. Rehydration was performed by washing in 100\%, 95\%, $80 \%$, and $70 \%$ ethanol for 10 minutes separately, at room temperature. Tumor tissue was separated from normal tissue with a needle, and was then inserted into an Eppendorf tube. DNA was extracted from the microdissected tissues using $200 \mathrm{uL}$ of proteinase $\mathrm{K}$ solution (190 uL of protein kinase digestion buffer with $10 \mathrm{uL}$ of 10 $\mathrm{mg} / \mathrm{mL}$ proteinase $\mathrm{K}$ ) in lysis buffer containing $0.5 \%$ Tween-20, $1 \mathrm{M}$ Tris (pH 8.5), and $500 \mathrm{mM}$ EDTA (pH 8.0). Tissues were incubated overnight in lysis buffer solution at $55^{\circ} \mathrm{C}$. After the overnight incubation, centrifugation was performed at 14,000 rpm for 15 minutes at $4^{\circ} \mathrm{C}$.

\section{Analysis of $\mathrm{MSI}$}

MSI was analyzed by PCR amplification with fluorescent dye-labeled primers of mononucleotide markers (BAT25 and BAT26) and dinucleotide markers (D2S123, D5S346, and D17S250) specific for the microsatellite loci. Primer sequences of the $\mathrm{MSI}$ markers are shown in table 1. As previously described, PCR was performed over 35 cycles of: 1 minute at $94^{\circ} \mathrm{C}, 1$ minute at $55^{\circ} \mathrm{C}$, and 1 minute at $72^{\circ} \mathrm{C}$ for the BAT25 and BAT26 primers ${ }^{16)}$. For D2S123, PCR was performed over 35 cycles of: 30 seconds at $94^{\circ} \mathrm{C}, 1$ minute at $54^{\circ} \mathrm{C}$, and 1 minute at $72^{\circ} \mathrm{C}$. For D5S346, PCR was performed over 36 cycles of: 30 seconds at $94^{\circ} \mathrm{C}, 30$ seconds at $55^{\circ} \mathrm{C}$, and 30 
Table 2. Clinicopathological findings in high microsatellite instability (MSI-H) and low microsatellite instability (MSI-L) cases

\begin{tabular}{|c|c|c|c|}
\hline & $\mathrm{MSSI}-\mathrm{H}^{\dagger}$ & $\overline{\mathrm{MSI}-\mathrm{L}^{\ddagger}}$ & $p$-value \\
\hline Male : Female & $8: 6$ & $10: 4$ & NS \\
\hline Age (mean \pm SD) & $66.7 \pm 13.0$ & $67.9 \pm 12.5$ & NS \\
\hline Intestinal : Diffuse ${ }^{*}$ & $11: 3$ & $3: 11$ & 0.007 \\
\hline Antrum : Cardia & $9: 5$ & $5: 9$ & NS \\
\hline Stage IB & 1 & 1 & NS \\
\hline$\|$ & 7 & 2 & \\
\hline$\| I A$ & 2 & 2 & \\
\hline IIIB & 4 & 6 & \\
\hline IV & 0 & 3 & \\
\hline
\end{tabular}

A

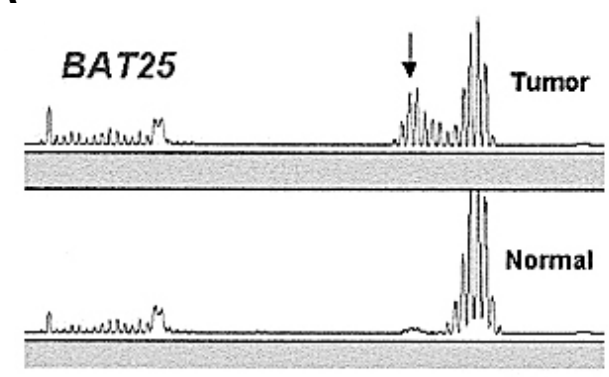

C

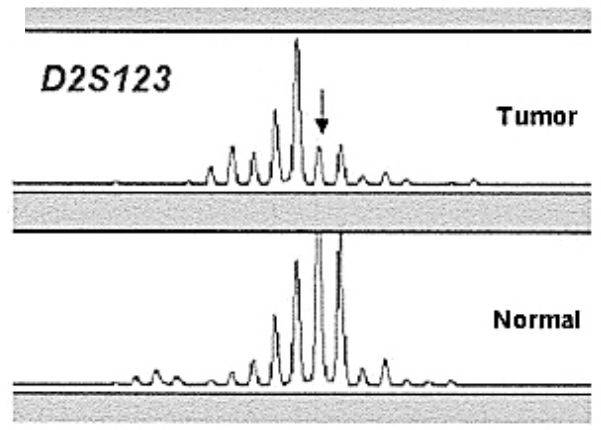

B

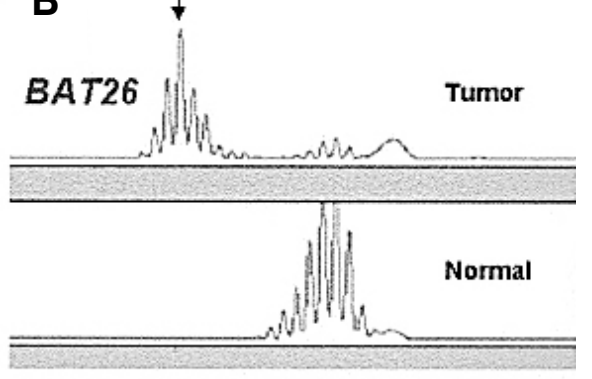

D

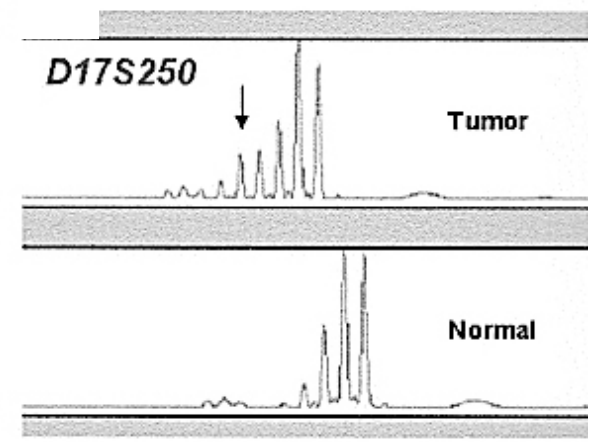

Figure 1. Detection of MSI by analysis of microsatellite markers in tumors and in corresponding normal tissue. Mutant alleles are indicated with arrows in each tumor trace: (A) BAT25, (B) BAT26, (C) D2S123, and (D) D17S250.

seconds at $72^{\circ} \mathrm{C}$. For D17S250, PCR was performed over 38 cycles of: 1 minute at $94^{\circ} \mathrm{C}, 1$ minute at $50^{\circ} \mathrm{C}$, and 1 minute at $72^{\circ} \mathrm{C}$. Fluorescently-labeled PCR products were detected using the ABI 3100 Genetic Analyzer (Applied Biosystems, Foster City, CA, USA) and Genescan software (Applied Biosystems, Foster City, CA, USA).

Electropherograms were analyzed independently by two different investigators. MSI was defined as a band shift in either of the two alleles or in the appearance of a differently-sized band in the tumor sample (Figure 1). Microsatellite genotypes were categorized as a high incidence of $\mathrm{MSI}(\mathrm{MSI}-\mathrm{H})$ when instability was detected in more than $30 \%$ of markers and as a low incidence of $\mathrm{MSI}$ (MSI-L) when instability was detected in less than $30 \%$ of markers ${ }^{28)}$.

Immunohistochemical staining and analysis

Immunohistochemical staining for $h M L H 1$ and $h M S H 2$ protein was performed as previously described ${ }^{29)}$. Losses of $h M L H 1$ and $h M S H 2$ protein expressions were determined by immunohistochemical staining. Antibody to hMLH1 (SC-581; Santa Cruz 

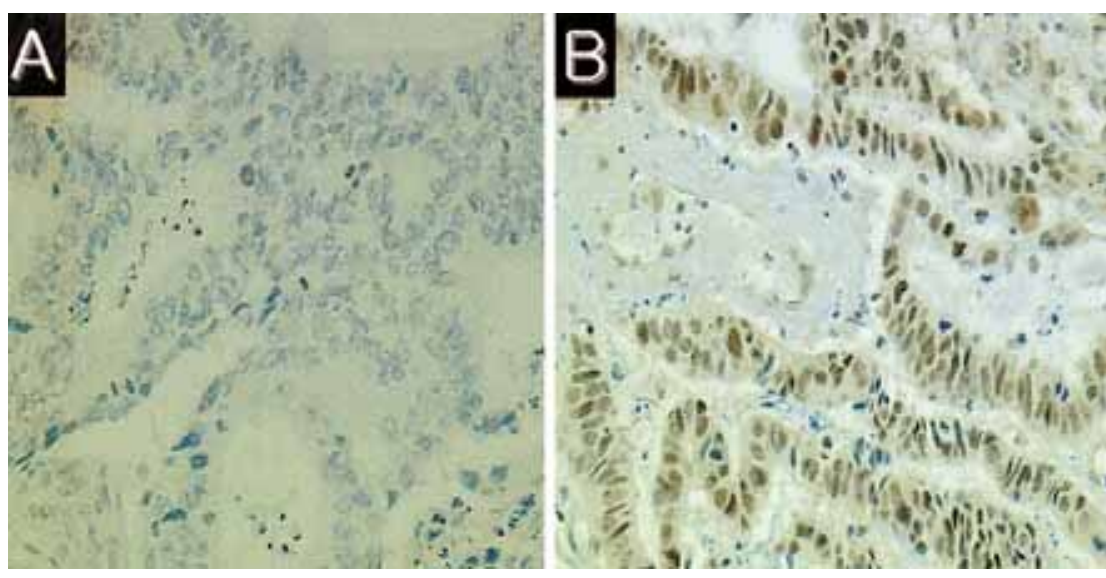

Figure 2. Immunohistochemical analysis of $h M L H 1$ in gastric cancer mucosa sections. (A) A MSI-H gastric cancer mucosa deficient in $h M L H 1$ protein $(\times 200)$. (B) A MSI-L gastric cancer mucosa showing strong $h M L H 1$ protein expression in the nuclei of cancer cells $(\times 200)$.

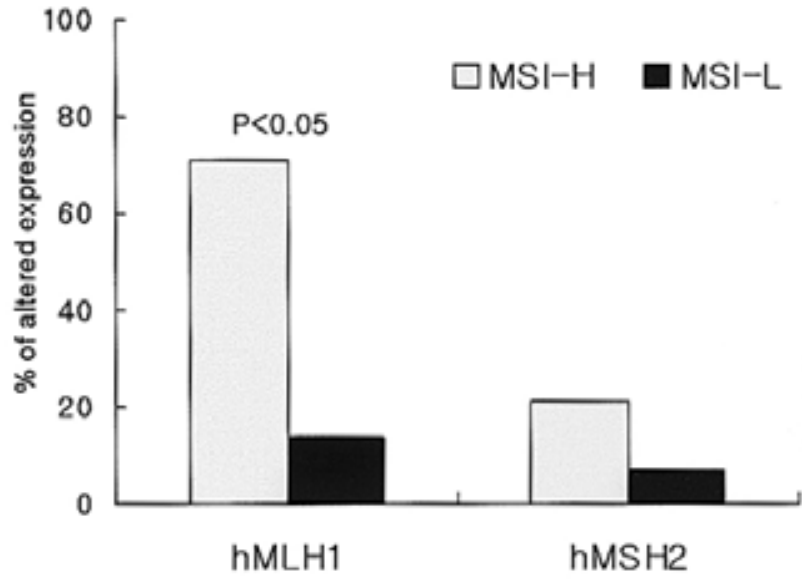

Figure 3. Summary of altered $h M L H 1$ and $h M S H 2$ protein expression. A loss of $h M L H 1$ protein was found to be significantly correlated with MSI status $(p=0.006)$.

Biotechnology INC, CA, USA), a rabbit polyclonal antibody, was prepared with a full-length $h M L H 1$ protein. Another rabbit polyclonal antibody, antibody to hMSH2 (SC-494; Santa Cruz Biotechnology INC, CA, USA), was generated via a $\mathrm{COOH}$ terminal fragment of $h M S H 2$ protein. As previously described ${ }^{29)}$, LOVO cells, which express $h M L H 1$, were stained simultaneously as a positive control.

\section{Statistics}

The possible association between MSI status and histology was assessed using Fisher's exact test. The chi-square test and Fisher's exact test were used for statistical assessment of the association between MSI status and clinicopathological profiles. The Kaplan-Meier method was used to estimate the survival probability as a function of time. The log-rank test (generalized Wilcoxon's test) was performed in order to analyze the differences in patient survival. A $p$-value less than 0.05 was accepted as statistically significant.

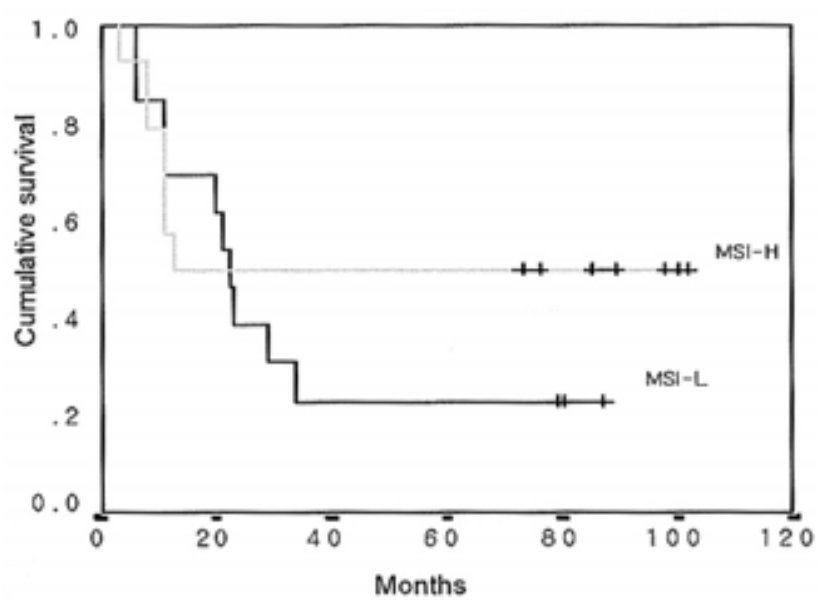

Figure 4. Survival analysis of cause-specific death from gastric cancer. The MSI-H group tended to have better survival than the MSI-L group, but it was not statistically significant $(p=0.17)$.

\section{RESULTS}

Of the 28 cases, 14 cases (50\%) manifested as MSI-H, while the other 14 cases were classified as MSI-L. Among the MSI-L cases, 8 showed no MSI (Table 2). MSI-H was more frequently observed in adenocarcinomas of the intestinal-type $(11 / 14)$ than in those of the diffuse-type $(3 / 14)(78 \%$ and $21 \%$, respectively, $p=0.007$ ). There was no statistically significant correlation between MSI status and sex, age, location of the tumor, or tumor stage (Table 2). According to each of the markers, there was no significant difference between the intestinal-type and the diffuse-type in BAT25 $(p=0.42)$, BAT26 $(p=1.00)$, D2S123 $(p=0.26)$, D5S346 $(p=0.21)$, and D17S250 $(p=0.24)$.

Immunohistochemical staining results on two mismatch repair proteins revealed strong correlations with MSI status (Figure 2). In MSI-H tumors, 10 cases $(71 \%)$ showed losses of $h M L H 1$ 
protein expression and 3 cases (21\%) showed losses of hMSH2 protein expression. In MSI-L tumors, 2 cases (14\%) showed losses of $h M L H 1$ protein expression and 1 case $(7 \%)$ showed a loss of $h M S H 2$ protein expression (Figure 3). A loss of $h M L H 1$ protein expression was significantly correlated with MSI status ( $p=0.006)$.

After gastrectomy, 8 patients among $14 \mathrm{MSI}-\mathrm{H}$ cases and 7 patients among $14 \mathrm{MSI}-\mathrm{L}$ cases underwent adjunctive chemotherapy with or without radiotherapy. Follow-up intervals after surgical resection ranged from 73 to 102 months with a median of 87 months in 10 patients who were alive throughout follow-up. Furthermore, follow-up times ranged from 3 to 34 months with a median of 15 months in 18 patients who died of gastric cancer. Using the Kaplan-Meier method, the survival curves of patients at all stages were plotted using MSI status (Figure 4). The MSI-L group exhibited lower survival, whereas the $\mathrm{MSI}-\mathrm{H}$ group revealed better survival. However, there was no statistically significant difference between the MSI-H group and the MSI-L group in cumulative survival $(p=0.17)$.

\section{DISCUSSION}

In the present study, MSI was observed more frequently than in previous reports ${ }^{10,12,17,21-25)}$, and $\mathrm{MSI}-\mathrm{H}$ was more frequently observed in the intestinal-type than in the diffusetype adenocarcinomas. This discrepancy is probably related to the definition and the methods of describing MSI, the patient population that underwent evaluation, and our small sample size. In spite of this unexpected data, our report is supported by previous studies which reported that MSI is more frequently observed in the intestinal-type ${ }^{10,12,17,21-25)}$. It is reported that the intestinal-type is prevalent in high-risk populations of gastric adenocarcinoma ${ }^{19)}$. Moreover, a previous study concluded that $\mathrm{MSI}$ is associated with the intestinal histological type and chromosomal deletion, which in turn lead to an increase in alterations of cancer-related genes ${ }^{30}$. This close relationship between $\mathrm{MSI}$ and intestinal-type gastric cancer may also suggest a genetic model common to colon and gastric cancers $^{17)}$. Intestinal metaplasia has been considered a precancerous lesion of intestinal-type gastric carcinoma ${ }^{19)}$, and MSI-associated mutations were detected exclusively in both intestinal-type gastric carcinomas and colon cancers. Thus, these two cancers appear to be closely related to each other histopathologically, as well as genetically ${ }^{22)}$.

However, these findings are inconsistent in regards to the association between $\mathrm{MSI}$ and these two pathological features. Replication error-positive phenotypes were more frequently observed in scirrhous-type gastric cancer $(75 \%)$ than in other histologic types, which suggests that scirrhous-type gastric cancers may have germline gene mutations in their DNA mismatch repair systems, such as $h M S H 2$ or $h M L H 1^{10)}$. Moreover, MSI was detected in $57 \%$ of the foveolar-type and $8 \%$ of intestinal-type ${ }^{26)}$. These findings suggest that foveolartype tumors contain several histopathological problems and are prone to losing their glandular structure and progressing to undifferentiated-type tumors. Thus, they should be regarded as precursors of undifferentiated-type tumors ${ }^{26)}$. They concluded that the 'mutator pathway', characterized by MSI, plays an important role in the tumorigenesis of foveolar-type tumors, but not in the complete-type intestinal metastatic phenotype ${ }^{27)}$. In addition to discrepancies due to different definitions of $\mathrm{MSI}$ cancer, the different results in terms of the MSI and intestinal/ diffuse histotype may reflect ethnic, racial, or geographic differences.

The aforementioned study ${ }^{24)}$ demonstrated that there appear to be three different profiles of carcinogenesis: 1) p53 mutations which accompany the onset of dysplasia and intestinal-type carcinoma; 2) alterations of E-cadherin, both with regards to mutations and abnormal expression; and 3) DNA repair mechanism alterations which condition microsatellite instability seem mutually exclusive with regards to p53 mutations. These alterations are correlated with antrally located intestinal-type carcinoma, with little metastatic tendency and a better prognosis. Some studies have reported that RER-positive cases mostly consisted of intestinal tumors and have been shown to carry relatively good prognose ${ }^{21,31-35)}$. In the present study, the MSI-H group tended to have better survival and a more favorable prognosis, but this finding was not statistically significant. Although there exists a report which suggests the irrelevance between survival and MSI status ${ }^{36)}$, our result, like that of previous studies, indicates that MSI seems to improve survival. Unfortunately, we were unable to statistically demonstrate it because the number of patients was too small.

Immunohistochemical staining is a consistent element in the study of MSI. A previous study demonstrated that immunohistochemistry could accurately discriminate between $\mathrm{MSI}-\mathrm{H}$ and microsatellite stable tumors ${ }^{37)}$. Moreover, the majority of germline mutations have been found in key MMR proteins, i.e., $h M L H 1$ and $h M S H 2$ proteins ${ }^{6)}$. In the present study, immunostaining for the loss of $h M L H 1$ protein expression revealed a significant correlation between its loss and MSI status ( $p=0.006$ ), suggesting that promoter hypermethylation of $h M L H 1$ might be correlated with a loss of $h M L H 1$ protein expression, which results in MSI, especially in intestinal-type gastric adenocarcinoma.

In summation, MSI was more observed more frequently in adenocarcinomas of the intestinal-type. This suggests that the intestinal- and diffuse-types of gastric adenocarcinoma, by Lauren's classification, are associated with different molecular carcinogenic pathways. Furthermore, our results suggest the 
importance of the $h M L H 1$ promoter in causing $\mathrm{MSI}-\mathrm{H}$ gastric cancer, and imply that the loss of $h M L H 1$ protein expression is related with intestinal-type gastric adenocarcinoma. Moreover, our results indicate that $h M L H 1$ protein expression analysis should be considered for the assessment of MSI-H status.

\section{REFERENCES}

1) Correa P. Human gastric carcinogenesis: a multistep and multifactorial process. Cancer Res 52:6735-6740, 1992

2) Seregni E, Ferrari L, Martinetti A, Bombardieri E. Diagnostic and prognostic tumor markers in the gastrointestinal tract. Semin Surg Oncol 20:147-166, 2001

3) Aaltonen LA, Peltomaki P, Leach FS, Sistonen P, Pylkkanen L, Mecklin JP, Jarvinen H, Powell SM, Jen J, Hamilton SR, Petersen GM, Kinzler KW, Vogelstein B, Chapelle A. Clues to the pathogenesis of familial colorectal cancer. Science 260:812-816, 1993

4) Ionov $Y$, Peinado MA, Malkhosyan S, Shibata D, Perucho M. Ubiquitous somatic mutations in simple repeated sequences reveal a new mechanism for colonic carcinogenesis. Nature 363:558-561, 1993

5) Strickler JG, Zheng J, Shu Q, Burgart LJ, Alberts SR, Shibata D. p53 mutations and microsatellite instability in sporadic gastric cancer: when guardians fail. Cancer Res 54:4750-4755, 1994

6) Halling KC, Harper J, Moskaluk CA, Thibodeau SN, Petroni GR, Yustein AS, Tosi P, Minacci C, Roviello F, Piva P, Hamilton SR, Jackson CE, Powell SM. Origin of microsatellite instability in gastric cancer. Am J Pathol 155:205-211, 1999

7) Hayden JD, Martin IG, Cawkwell L, Quirke P. The role of microsatellite instability in gastric carcinoma. Gut 42:300-303, 1998

8) Semba S, Yokozaki H, Yamamoto S, Yasui W, Tahara E. Microsatellite instability in precancerous lesions and adenocarcinomas of the stomach. Cancer 77:1620-1627, 1996

9) Kim HG, Yang JH, Choi BR, Lee CH, Bae JD, Cho CH, Chung WB, Hong SH, Kim JA, Kim JW, Sohn YK. Microsatellite instability in gastric adenocarcinoma tissue obtained by endoscopic biopsy. Korean J Gastroenterol 35:579-590, 2000

10) Choi SW, Choi JR, Chung YJ, Kim KM, Rhyu MG. Prognostic implications of microsatellite genotypes in gastric carcinoma. Int $\mathrm{J}$ Cancer 89:378-383, 2000

11) Kang $\mathrm{YH}$, Bae SI, Kim WH. Comprehensive analysis of promoter methylation and altered expression of hMLH1 in gastric cancer cell lines with microsatellite instability. J Cancer Res Clin Oncol 128:119-124, 2002

12) Kim HS, Lee BL, Woo DK, Bae SI, Kim WH. Assessment of markers for the identification of microsatellite instability phenotype in gastric neoplasms. Cancer Lett 164:61-68, 2001

13) Kim KM, Kwon MS, Hong SJ, Min KO, Seo EJ, Lee KY, Choi SW, Rhyu MG. Genetic classification of intestinal-type and diffuse-type gastric cancers based on chromosomal loss and microsatellite instability. Virchows Arch 443:491-500, 2003

14) Kim JJ, Baek MJ, Kim L, Kim NG, Lee YC, Song SY, Noh SH, Kim $\mathrm{H}$. Accumulated frameshift mutations at coding nucleotide repeats during the progression of gastric carcinoma with microsatellite instability. Lab Invest 79:1113-1120, 1999

15) Lim S, Lee HS, Kim HS, Kim YI, Kim WH. Alteration of E-cadherin- mediated adhesion protein is common, but microsatellite instability is uncommon in young age gastric cancers. Histopathology 42:128-136, 2003

16) Sepulveda AR, Santos AC, Yamaoka Y, Wu L, Gutierrez O, Kim JG, Graham DY. Marked differences in the frequency of microsatellite instability in gastric cancer from different countries. Am J Gastroenterol 94:3034-3038, 1999

17) Chung YJ, Kim KM, Choi JR, Choi SW, Rhyu MG. Relationship between intratumor histological heterogeneity and genetic abnormalities in gastric carcinoma with microsatellite instability. Int J Cancer 82:782-788, 1999

18) Lauren $P$. The two histological main types of gastric carcinoma: diffuse and so-called intestinal-type carcinoma an attempt at a histo-clinical classification. Acta Pathol Microbiol Scand 64:31-49, 1965

19) Correa $\mathrm{P}$, Shiao $\mathrm{YH}$. Phenotypic and genotypic events in gastric carcinogenesis. Cancer Res 54:1941s-1943s, 1994

20) Solcia E, Fiocca R, Luinetti O, Villani L, Padovan L, Calistri D, Ranzani GN, Chiaravalli A, Capella C. Intestinal and diffuse gastric cancers arise in a different background of Helicobacter pylori gastritis through different gene involvement. Am J Surg Pathol 20:S8-S22, 1996

21) dos Santos NR, Seruca R, Constancia M, Seixas M, Sobrinho-Simoes M. Microsatellite instability at multiple loci in gastric carcinoma: clinicopathologic implications and prognosis. Gastroenterology 110:3844, 1996

22) Chung YJ, Song JM, Lee JY, Jung YT, Seo EJ, Choi SW, Rhyu MG. Microsatellite instability associated mutations associate preferentially with the intestinal type of primary gastric carcinomas in a high risk population. Cancer Res 56:4662-4665, 1996

23) Buonsanti G, Calistri D, Padovan L, Luinetti O, Fiocca R, Solcia E, Ranzani GN. Microsatellite instability in intestinal- and diffuse-type gastric carcinoma. J Pathol 182:167-173, 1997

24) Fiocca R, Luinetti O, Villani L, Mastracci L, Quilici P, Grillo F, Ranzani GN. Molecular mechanisms involved in the pathogenesis of gastric carcinoma: interactions between genetic alterations, cellular phenotype and cancer histotype. Hepatogastroenterology 48:1523-1530, 2001

25) Wu MS, Lee CW, Shun CT, Wang HP, Lee WJ, Sheu JC, Lin JT. Clinicopathological significance of altered loci of replication error and microsatellite instability-associated mutations in gastric cancer. Cancer Res 58:1494-1497, 1998

26) Endoh $Y$, Tamura G, Ajioka $Y$, Watanabe H, Motoyama T. Frequent hypermethylation of the $h M L H 1$ gene promoter in differentiated-type tumors of the stomach with the gastric foveolar phenotype. Am J Pathol 157:717-722, 2000

27) Endoh $Y$, Sakata K, Tamura G, Ohmura K, Ajioka $Y$, Watanabe $H$, Motoyama T. Cellular phenotypes of differentiated-type adenocarcinomas and precancerous lesions of the stomach are dependent on the genetic pathways. J Pathol 191:257-263, 2000

28) Boland CR, Thibodeau SN, Hamilton SR, Sidransky D, Eshleman JR, Burt RW, Meltzer SJ, Rodriguez-Bigas MA, Fodde R, Ranzani GN, Srivastava S. A National Cancer Institute Workshop on Microsatellite Instability for cancer detection and familial predisposition: development of international criteria for the determination of microsatellite instability in colorectal cancer. Cancer Res 58:5248-5257, 1998

29) Kang GH, Shim YH, Ro JY. Correlation of methylation of the $h M L H 1$ promoter with lack of expression of $h M L H 1$ in sporadic gastric carcinomas with replication error. Lab Invest 79:903-909, 1999

30) Rhyu MG. Genetic events underlying morphological complexity of 
gastric carcinoma. J Korean Med Sci 13:339-349, 1998

31) Luinetti O, Fiocca R, Villani L, Alberizzi P, Ranzani GN, Solcia E. Genetic pattern, histological structure and cellular phenotype in early and advanced gastric cancers: evidence for structure-related genetic subsets and for loss of glandular structure during progression of some tumors. Hum Pathol 29:702-709, 1998

32) Choi SW, Choi JR, Chung YJ, Kim KM, Rhyu MG. Prognostic implications of microsatellite genotypes in gastric carcinoma. Int $\mathrm{J}$ Cancer 89:378-383, 2000

33) Schneider BG, Bravo JC, Roa JC, Roa I, Kim MC, Lee KM, Plaisance $\mathrm{KT} \mathrm{Jr}$, McBride CM, Mera R. Microsatellite instability, prognosis and metastasis in gastric cancers from a low-risk population. Int J Cancer 89:444-452, 2000

34) Chiaravalli AM, Cornaggia M, Furlan D, Capella C, Fiocca R, Tagliabue G, Klersy C, Solcia E. The role of histological investigation in prognostic evaluation of advanced gastric cancer: analysis of histological structure and molecular changes compared with invasive pattern and stage. Virchows Arch 439:158-169, 2001

35) Wu MS, Lee CW, Sheu JC, Shun CT, Wang HP, Hong RL, Lee WJ, Lin JT. Alterations of BAT-26 identify a subset of gastric cancer with distinct clinicopathologic features and better postoperative prognosis. Hepatogastroenterology 49:285-289, 2002

36) Wirtz HC, Muller W, Noguchi T, Scheven M, Ruschoff J, Hommel G, Gabbert HE. Prognostic value and clinicopathological profile of microsatellite instability in gastric cancer. Clin Cancer Res 4:1749-1754, 1998

37) Marcus VA, Madlensky L, Gryfe R, Kim H, So K, Millar A, Temple LK, Hsieh E, Hiruki T, Narod S, Bapat BV, Gallinger S, Redston M. Immunohistochemistry for hMLH1 and hMSH2: a practical test for DNA mismatch repair-deficient tumors. Am J Surg Pathol 23:1248-1255, 1999 